Jurnal ECOTIPE, Volume 7, No.1, April 2020, Hal. 26-37

p-ISSN 2355-5068, e-ISSN 2622-4852

Akreditasi Kemenristekdikti (SINTA 4), SK. No.10/E/KPT/2019

DOI: 10.33019/ecotipe.v7i1.1384

\title{
Teknik Fast Charging Baterai Lithium-Ion Menggunakan Logika Fuzzy
}

\author{
Amar Anshori ${ }^{1}$, Bambang Siswojo ${ }^{2}$, Rini Nur Hasanah ${ }^{3}$ \\ ${ }^{1,2,3}$ Fakultas Teknik, Jurusan Teknik Elektro, Sitem Kontrol dan Elektronik, Universitas Brawijaya \\ Email: amarsciencethink@gmail.com, bsiswoyo@ub.ac.id, rini.hasanah@ub.ac.id
}

\begin{abstract}
The increasing use of portable electronic equipment uses more and more lithium-ion batteries. Issues that occur from increased use of the battery pose problems such as less capacity, long charging time, and overcharging protection. Some methods of lithium-ion battery charging techniques are commonly used such as Constan Voltage (CV), Constan Current (CC), CC-CV, and reflex charging methods. In this study the fast charging Lithium-ion battery technique uses fuzzy logic to control temperature and voltage during battery charging using the Pulse Width Modulation (PWM) Charging method, the fuzification process used Is Mamdani method with Center Of Gravity (COG) Defuzzification method. It is expected to accelerate the charging without making the battery temperature exceed the maximum limit, as well as the overcharging. The filling results using this Fast Charger using the fuzzy logic proved to accelerate charging and protect the occurrence of overcharging the battery.
\end{abstract}

Keywords : charger, fast charging, lithium-ion, fuzzy logic, overcharging, PWM

\section{INTISARI}

Meningkatnya penggunakan peralatan elektronik portable penggunaan baterai lithium-ion semakin banyak. Permasalahan yang terjadi dari meningkatnya penggunaan baterai menimbulkan masalah seperti kapasitas kurang besar, waktu pengisian lama, dan proteksi overcharging. Beberapa metode teknik pengisian baterai lithium-ion yang umum digunakan seperti metode Constan Voltage (CV), Constan Current (CC), CC-CV, dan reflex charging. Pada penelitian ini teknik fast charging baterai Lithium-ion menggunakan logika fuzzy untuk mengontrol temperatur dan tegangan pada saat melakukan pengisian baterai menggunakan metode pengisian Pulse Width Modulation (PWM), proses fuzifikasi yang digunakan adalah metode Mamdani dengan metode defuzzifikasi Center Of Gravity (COG). Diharapkan mampu mempercepat pengisian tanpa membuat temperatur baterai melebihi batas maksimal, serta mangatasi overcharging. Hasil pengisian menggunakan Fast Charger ini dengan menggunakan logika fuzzy terbukti dapat mempercepat pengisian dan melindungi terjadinya overcharging pada baterai.

Kata kunci: charger, fast charging, lithium-ion, logika fuzzy, overcharging, PWM

\section{PENDAHULUAN}

Dengan semakin meningkatnya penggunaan peralatan elektronik portable, penggunaan baterai yang dapat diisi ulang juga semakin banyak. Permintaan akan peningkatan kapasitas baterai yang lebih besar membuat beberapa produsen peralatan elektronik memperbesar kapasitas baterai sebagai solusi dengan cara menggunakan baterai Lithium-ion yang dapat menyimpan daya listrik lebih besar dari tipe baterai sebelumnya seperti baterai $\mathrm{NiCd}$ dan $\mathrm{NiMh}$ Chia-Hsiang Lin, $\mathrm{dkk},(2008)$.

Selain dari kapasitas baterai Lithium-ion yang lebih besar, ada juga kelebihan lain yang ada pada tipe baterai Lithium-ion seperti dimensi lebih kecil, kemampuan daya lebih besar, perawatan lebih mudah, dan tidak memiliki efek memori Houshyar Asadi, dkk, (2011). Karakteristik dari baterai Lithium-ion yang biasa digunakan antara lain tegangan minimal yang diperbolehkan $2,75 \mathrm{~V}$, tegangan maksimal $4,2 \mathrm{~V}$, hambatan dalam baterai saat pengukuran di AC 
Jurnal ECOTIPE, Volume 7, No.1, April 2020, Hal. 26-37

p-ISSN 2355-5068, e-ISSN 2622-4852

Akreditasi Kemenristekdikti (SINTA 4), SK. No.10/E/KPT/2019

DOI: 10.33019/ecotipe.v7i1.1384

$1 \mathrm{kHz}$ pada kapasitas baterai $50 \%$ sebesar $\leq 180 \mathrm{~m} \Omega$, sedangkan batas temperatur yang diperbolehkan pada saat charge $0 \sim 45^{\circ} \mathrm{C}$, dan pada saat discharge $-20 \sim 60^{\circ} \mathrm{C}$ EEMB Co, (2016). Akan tetapi hal tersebut menimbulkan masalah baru pada lamanya waktu yang dibutuhkan untuk melakukan pengisian baterai. Maka dari itu semua produsen bersaing dalam menawarkan solusi fast charging untuk pengisian baterai yang lebih cepat.

Perbedaan charging biasa dengan fast charging pada umumnya terletak pada lamanya waktu pengisian baterai, daya charger lebih besar dari charger biasa, dan pengembangan metode pengisiannya EEMB Co, (2016). Suatu charger yang baik harus mampu mengisi baterai dengan cepat tanpa merusak baterai. Untuk menjaga agar baterai selalu dalam kondisi yang baik maka diperlukan perawatan, termasuk memilih charger yang berkualitas karena usia baterai isi ulang dipengaruhi juga oleh pengisiannya.

Dengan adanya Fast Charger yang berkapasitas daya lebih besar memang dapat terisi lebih cepat dari charger biasa, namun terkadang terdapat konsumen yang kurang memperdulikan waktu optimal pengisian baterai dan arahan untuk melepas soket charger ketika baterai sudah penuh, sehingga mengakibatkan overcharging pada saat pengisian. Hal tersebut yang dapat mengakibatkan berkurangnya umur baterai dikarenakan kenaikan temperatur melebihi batas yang diperbolehkan. Selain dapat memperpendek umur baterai juga dapat mengakibatkan baterai meledak. Supaya baterai tidak mengalami overcharging, maka harus ada mekanisme untuk memonitor dan mengontrol kerja dari charger. Beberapa metode yang sering digunakan antara lain metode tegangan konstan, arus konstan, multistage, monitor percepatan kenaikan temperatur, monitor percepatan kenaikan tekanan baterai dan negative delta voltage.

Pada penelitian J. López, dkk, (2004) dilakukan pengujian baterai Lithium-ion 0,7A secara intensif di tingkat pengisian dari $\mathrm{C} / 3$ sampai $1.5 \mathrm{C}$, dan suhu $23^{\circ} \mathrm{C}$. Perubahan parameter yang dilihat antara lain tegangan, arus, dan suhu. Kemudian data diolah untuk melihat dampak dari perbedaan pengisian baterai. dari hasil pengujian pada saat tingkat pengisian $1.5 \mathrm{C}$ membutuhkan waktu 45 menit, sedangkan pada tingkat pengisian $\mathrm{C}$ (Capacity) membutuhkan waktu 60 menit. Namun ketika tingkat pengisian $>\mathrm{C}$ digunakan, suhu baterai meningkat di atas suhu ruangan. Pengontrol suhu harus ditambahkan untuk melindungi berkurangnya masa pakai baterai dan berkurangnya efisiensi energi pada saat proses pengisian.

Chia-Hsiang Lin, dkk, (2008) melakukan penelitian menggunakan metode arus konstan ke tegangan konstan, pada penelitian ini yang diperpanjang adalah periode arus konstannya untuk mempercepat pengisian dengan merubah tegangan referensi, maka charger dapat menunda waktu mode pengoperasian dari arus konstan ke tegangan konstan. Hasil simulasi memverfikasi keberhasilan teknik fast charging kompensasi resistansi internal. Dalam jurnal C. K. Leong, $\mathrm{dkk}$, (2010) digunakan metode pengisian dengan cara memberi pulsa positif satu detik dan di nol kan 20-30ms diikuti pulsa negatif pada tengah waktu di nol kan. Dalam jurnal penelitian serupa Houshyar Asadi, dkk, (2011) melakukan eksperimen dengan menggunakan metode pengisian menggunakan AC impedance technique yang outputannya dikontrol menggunakan logika fuzzy. Dengan metode tersebut dapat ditingkatkan efisiensi pengisian baterai dan dikurangi temperatur yang berlebih, sehingga dapat diperpanjang umur baterai.

Mengacu pada latar belakang yang telah dipaparkan, perbedaan dengan penelitian Houshyar Asadi, dkk, (2011) logika kontrol yang digunakan adalah logika fuzzy dan metode pengisiannya AC impedance untuk mengukur hambatan dalam baterai menggunakan frekuensi switching sebesar $2 \mathrm{kHz}$. Parameter input yang digunakan sensor tegangan, arus, dan temperatur. 
Jurnal ECOTIPE, Volume 7, No.1, April 2020, Hal. 26-37

p-ISSN 2355-5068, e-ISSN 2622-4852

Akreditasi Kemenristekdikti (SINTA 4), SK. No.10/E/KPT/2019

DOI: 10.33019/ecotipe.v7i1.1384

Fuzzifikasi input menggunakan $\mathrm{T}$ temperatur dan $\Delta \mathrm{T}$ temperatur, metode defuzzifikasi center of gravity (COG) mengklaim dapat mempercepat pengisian baterai dengan temperatur lebih rendah dan efisiensi mencapai $97.16 \%$ dari penelitian sebelumnya. EEMB Co, (2016) melakukan percobaan fast charging menggunakan metode Constan Current (CC) sebesar 1C5A, Constan Voltage (CV) 4,2V, dan arus cut-off sebesar $0.01 \mathrm{CA}$ didapat lama waktu pengisian $2,5 \mathrm{~h}$ dengan range temperatur pada saat pengisian 0 $45^{\circ} \mathrm{C}$.

Pada penelitian ini peneliti ingin menggunakan logika kontrol fuzzy teknik pengisian PWM (Pulse Width Modulation) untuk mengontrol temperatur dan tegangan pada saat melakukan pengisian baterai. Proses fuzifikasi yang digunakan adalah metode Mamdani dengan variable masukan dari temperatur dan tegangan dengan metode defuzzifikasi Center Of Gravity (COG) keluaran fuzzy berupa pulsa PWM ( ). Diharapkan dengan adanya teknik fast charging baterai Lithium-ion menggunakan logika fuzzy ini mampu dipercepat pengisian tanpa membuat temperatur baterai melebihi batas maksimal, serta mangatasi overcharging.

\section{LANDASAN TEORI}

\section{A. Kerangka Penelitian}

Dari beberapa penelitian dan datasheet baterai Lithium-ion terkait metode pengisian (charging) baterai yang pernah dilakukan diantaranya, pertama dengan menunda waktu perpindahan antara mode pengisian Constant Voltage (CV) dengan memperpanjang waktu pengisian Constant Current (CC) supaya energi yang diserap oleh baterai lebih banyak Chia-Hsiang Lin, dkk, (2008), namun dengan memperpanjang waktu pengisian $\mathrm{CC}$ temperatur baterai akan naik sangat cepat dan hal ini yang mengakibatkan baterai cepat rusak. Kedua EEMB Co, (2016) pengisian standard yang terdapat pada data sheet baterai Lithium-ion dengan arus metode Constant Current (CC) dan Constant Voltage (CV), dimana pada saat mode $\mathrm{CC}$ arus yang masuk $0,5 \mathrm{C}$ (Capacity) setelah itu ketika kapasitas baterai mencapai $85 \%$ pengisan akan berubah ke mode $\mathrm{CV}$ sebesar $4,2 \mathrm{~V}$ dan temperatur baterai ada pada range $0 \sim 45^{\circ} \mathrm{C}$. Pengisan akan berhenti ketika tegangan baterai mencapai $4,2 \mathrm{~V}$ atau arus yang masuk pada baterai sebesar 0,01C, waktu pengisian menggunakan metode ini $6 \mathrm{~h}$. Kemudian EEMB Co, (2016) melakukan percobaan fast charging menggunakan metode Constan Current (CC) sebesar 1,5C, Constan Voltage (CV) 4,2V, dan arus cut-off sebesar $0.01 \mathrm{C}$ didapat lama waktu pengisian $2,5 \mathrm{~h}$ dengan range temperatur pada saat pengisian $0-45^{\circ} \mathrm{C}$.

Jingyu Yan, dkk, (2010) state of charge (SoC), J. Lopez, dkk, (2004) memperbesar Capacity (C) pengisian, Houshyar Asadi, dkk, (2011) AC impedance, C.K.Leong, dkk, (2010) Indar Sugiarto, dkk, (2004) reflex charging/pulse/ Mc. Culloch dengan negative delta voltage regulation, dan Yong-Duk Lee, dkk, (2013) multi stage current. Dari beberapa metode pengisian baterai semua tertuju pada kenaikan temperatur, karena jika temperatur melebihi batas yang sudah ditentukan baterai dapat rusak, meledak, kembung, dan umur baterai berkurang.

Dalam Penelitian ini penulis mencoba mengusulkan sebuah pengembangan pada metode pengisian baterai Lithium-ion untuk mempercepat pengisian yang aman tanpa merusak baterai dan memproteksi ketika terjadi overcharging. Komputasi yang akan digunakan untuk fast charging adalah logika fuzzy. Logika fuzzy digunakan untuk memproses input data dari sensor temperatur dan tegangan yang diperoleh dari hasil pengukuran pada saat melakukan pengisian baterai. Keluaran fuzzy yang berupa nilai real (crisp) akan dirubah menjadi sinyal pulsa PWM (Pulse Width Modulation) untuk mengisi baterai. 
Jurnal ECOTIPE, Volume 7, No.1, April 2020, Hal. 26-37

p-ISSN 2355-5068, e-ISSN 2622-4852

Akreditasi Kemenristekdikti (SINTA 4), SK. No.10/E/KPT/2019

DOI: 10.33019/ecotipe.v7i1.1384

\section{B. Perancangan Sensor Tegangan}

Rangkaian pembagi tegangan (voltage divider) digunakan untuk pembacaan data tegangan pada baterai.

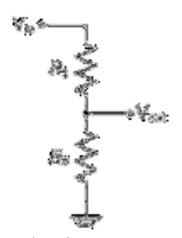

Gambar 1. Rangkaian Pembagi Tegangan

Rangkaian pembagi tegangan digunakan untuk membuat suatu tegangan referensi dari sumber tegangan yang lebih besar untuk titik tegangan referensi pada sensor. Pin ADC Arduino memiliki batasan pembacaan tegangan sebesar 5V. Oleh karena itu, rangkaian pembagi tegangan (voltage divider) digunakan untuk memperkecil tegangan sesuai dengan perbandingan yang telah dihitung.

\section{Perancangan Sensor Inframerah MLX90614}

Untuk mengambil data temperatur pada sistem charger ini digunakan sensor temperatur dengan tipe MLX90614 seperti gambar di atas. Sensor inframerah MLX90614 merupakan sensor yang digunakan untuk mengukur temperatur dengan memanfaatkan radiasi gelombang inframerah. Sensor ini didesain khusus untuk mendeteksi radiasi inframerah dan secara otomatis telah didesain sehingga dapat mengkalibrasi energi radiasi inframerah menjadi skala temperature tanpa harus menyentuh/menempel pada benda yang akan di ukur. Data hasil pengukuran temperatur akan di outputkan melalui kaki pin SCL dan SDA ke Arduino.

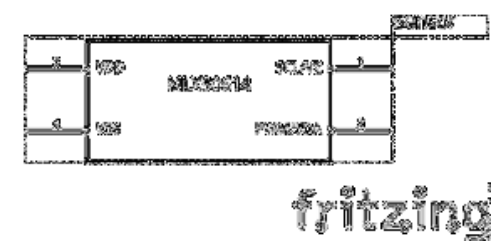

Gambar 2. Rangkaian Sensor Inframerah MLX90614

\section{Perancangan Software Arduino}

Penggunaan Arduino pada desain charger ini berfungsi mengubah pembacaan sinyal analog dari sensor tegangan menjadi sinyal digital dan membaca hasil outputan data sensor temperatur melalui kaki pin SCL dan SDA yang sudah berupa data temperatur string. Sinyal digital dan data string inilah yang nantinya dapat diolah menjadi data yang diperlukan dalam system.

\section{E. Perancangan Logika Fuzzy}

Penggunaan sensor tegangan sebagai output dari tegangan baterai dan temperatur sebagai output temperatur baterai. Dari data kedua sensor yang masih berupa nilai crisp akan di dirubah ke dalam himpunan fuzzy untuk menentukan derajat keanggotaannya di dalam himpunan fuzzy (fuzzifikasi). Fuzzy Inference System yang digunakan pada penelitian ini adalah metode Mamdani. Nilai yang masih berupa himpunan fuzzy akan dirubah kembali menjadi nilai crisp kembali (defuzzifikasi) berupa data output PWM dengan menggunakan metode Center Of Grafity (COG).

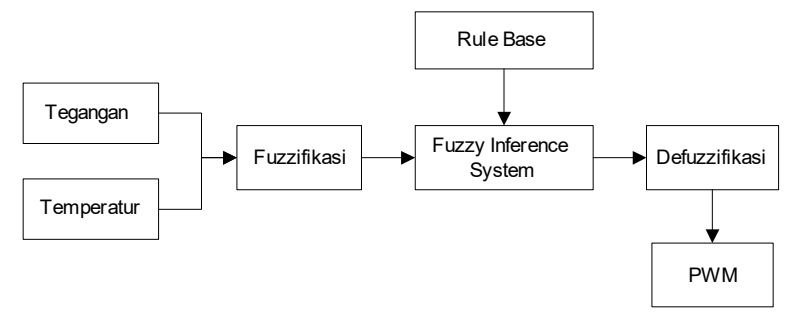

Gambar 3. Teknik Fast Charging Logika Fuzzy

\section{METODE PENELITIAN}

\section{A. Tahap Penelitian}

Seperti yang telah dipaparkan sebelumnya. Tahapan pada penelitian ini dilakukan dalam beberapa tahapan, yaitu: (1) Studi literatur, (2) Kalibrasi Sensor, (3) Desain Sistem, (4) Pembuatan Alat, (5) Analisis dan pengujian 
Jurnal ECOTIPE, Volume 7, No.1, April 2020, Hal. 26-37

p-ISSN 2355-5068, e-ISSN 2622-4852

Akreditasi Kemenristekdikti (SINTA 4), SK. No.10/E/KPT/2019

DOI: 10.33019/ecotipe.v7i1.1384

dan (6) Kesimpulan. Untuk lebih jelas dapat dilihat pada gambar 4.

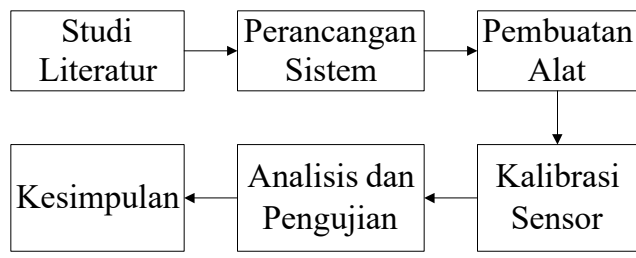

Gambar 4. Tahapan Penelitian

\section{B. Perancangan Sistem}

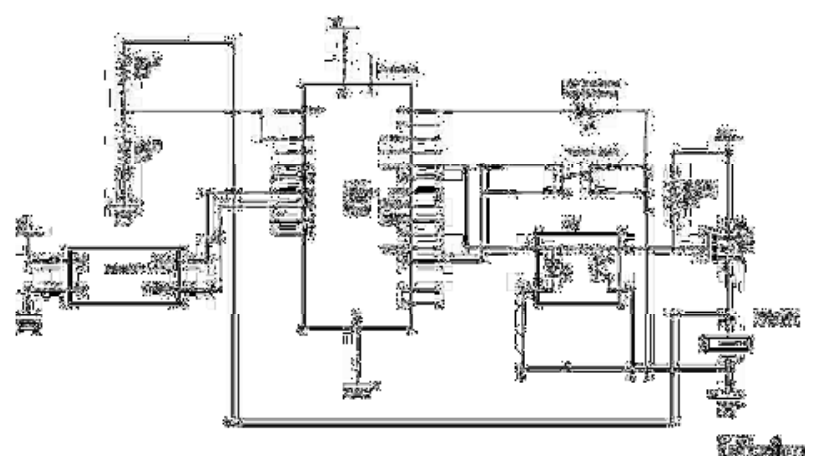

Gambar 5. Skematik Fast Charger

Cara kerja dari gambar 5 skematik Fast Charger di atas, Arduino adalah sebagai pengendali keseluruhan alat baik input sensor tegangan, temperatur, dan button start maupun output PWM dan LED indikator. Pada saat alat pertama kali dinyalakan jika tidak ada penekanan pada tombol button start charger tidak akan aktif dimana bisa dilihat pada LED indikator port D13 yang tidak menyala. Jika tombol button start ditekan, lampu LED indikator akan menyala lalu pembacaan sensor akan dilakukan mulai dari sensor tegangan akan dibaca oleh ADC pin A0 Arduino dan sensor temperatur akan mengirim data melalui pin SDA dan SCL Arduino. Setelah data input sudah terkumpul Arduino yang sudah terisi program algoritma logika fuzzy akan memproses data input lalu mengoutputkan sinyal PWM sesuai hasil perhitungan logika fuzzy melalui pin D9 untuk mengisi baterai melalui rangkaian switching. Ketika baterai sudah penuh Arduino akan menghentikan pengisian baterai dengan memberi nilai $\mathrm{PWM}=0$ dan lampu LED indikator akan mati.

Kontrol logika fuzzy pada bagian ini adalah untuk mengendalikan pengisian baterai. Variabel input yang digunakan adalah nilai temperatur dan tegangan baterai. Nilai temperatur digunakan sebagai pembanding dengan nilai tegangan, apakah output duty cycle PWM kecil atau besar. Logika fuzzy yang digunakan pada bagian ini adalah menggunakan metode mamdani. Desain kontrol logika fuzzy untuk fast charging dapat dilihat pada gambar 6 .

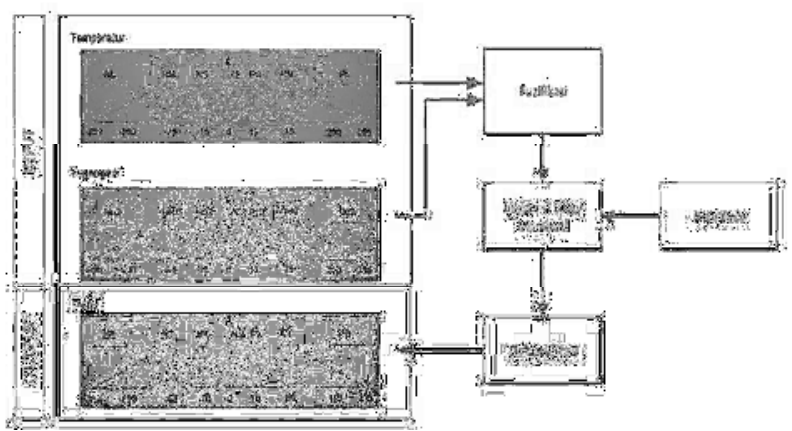

Gambar 6. Desain kontrol logika fuzzy untuk fast charging

Pada bagian ini variabel input dari dua jalur memiliki fungsi keanggotaan yang sama. Fungsi keanggotaan output adalah nilai PWM. Fungsi keanggotaan untuk masing-masing variabel adalah sebagai berikut:

Tabel 1. Variabel Linguistik Yang Digunakan

\begin{tabular}{|l|l|l|}
\hline \multicolumn{3}{|c|}{ Variabel Linguistik } \\
\hline Error Temperatur & \multicolumn{1}{|c|}{ Error Tegangan } & \multicolumn{1}{c|}{ PWM } \\
\hline NL : Negatif Large & NL2 : Negatif Large 2 & NB : Negatif Besar \\
\hline $\begin{array}{l}\text { NM : Negatif } \\
\text { Medium }\end{array}$ & $\begin{array}{l}\text { NM2 }: \text { Negatif Medium } \\
2\end{array}$ & $\begin{array}{l}\text { NT }: \text { Negatif } \\
\text { Tengah }\end{array}$ \\
\hline NS : Negatif Small & NS2 : Negatif Small 2 & NK : Negatif Kecil \\
\hline ZE : Zero & ZE2 : Zero 2 & Nol : Nol \\
\hline PS : Positif Small & PS2 $:$ Positif Small 2 & PK : Positif Kecil \\
\hline $\begin{array}{l}\text { PM : Positif } \\
\text { Medium }\end{array}$ & PM2 $:$ Positif Medium 2 & PT : Positif Tengah \\
\hline PL : Positif Large & PL2 $:$ Positif Large 2 & PB : Positif Besar \\
\hline
\end{tabular}


Jurnal ECOTIPE, Volume 7, No.1, April 2020, Hal. 26-37

p-ISSN 2355-5068, e-ISSN 2622-4852

Akreditasi Kemenristekdikti (SINTA 4), SK. No.10/E/KPT/2019

DOI: 10.33019/ecotipe.v7i1.1384

Set aturan (fuzzy rule) yang dipilih akan digambarkan dengan FAM (fuzzy associative Memories) yang merepresentasi aturan yang harus dipenuhi. Aturan linguistik PWM diperoleh berdasarkan variabel linguistik dari error temperatur dan error tegangan. Misalnya error yang terjadi pada sistem adalah NM (Negatif Medium) dan NS2 (Negatif Small 2) maka variabel linguistik untuk PWM dipilih PK (Positif Kecil), hal ini tergantung pada aturan yang dibentuk. FAM untuk fast charging digambarkan seperti tabel 2.

Tabel 2. Basis Aturan Logika Fuzzy (Error

Temperatur, Error Tegangan, dan PWM)

\begin{tabular}{|c|c|c|c|c|c|c|c|c|}
\hline & \multicolumn{8}{|c|}{ Error V } \\
\hline \multirow{8}{*}{$\begin{array}{c}\text { Error } \\
\mathbf{T}\end{array}$} & & NL2 & NM2 & NS2 & ZE2 & PS2 & PM2 & PL2 \\
\hline & NL & PB & PB & $\mathrm{PK}$ & Nol & PK & PB & PB \\
\hline & NM & PB & PT & PK & Nol & PK & PT & PB \\
\hline & NS & PK & PK & PK & Nol & PK & PK & PK \\
\hline & $\mathbf{Z E}$ & Nol & Nol & Nol & Nol & Nol & Nol & Nol \\
\hline & PS & NK & NK & NK & Nol & NK & NK & NK \\
\hline & $\mathbf{P M}$ & NB & NT & NK & Nol & NK & NT & NB \\
\hline & PL & NB & NB & NK & Nol & NK & NB & NB \\
\hline
\end{tabular}

\section{Kalibrasi Sensor}

Pada tahap kalibrasi sensor, alat yang digunakan adalah sensor temperatur, sensor tegangan, baterai Lithium-ion, Thermometer, Multimeter, Arduino, IDE Arduino, dan PC/Lapop. Tujuan mengkalibrasi sensor terlebih dahulu ialah, supaya ketika melakukan pengukuran baik temperatur atau tegangan pada baterai tidak salah. Berikut cara melakukan kalibrasi sensor tersebut:

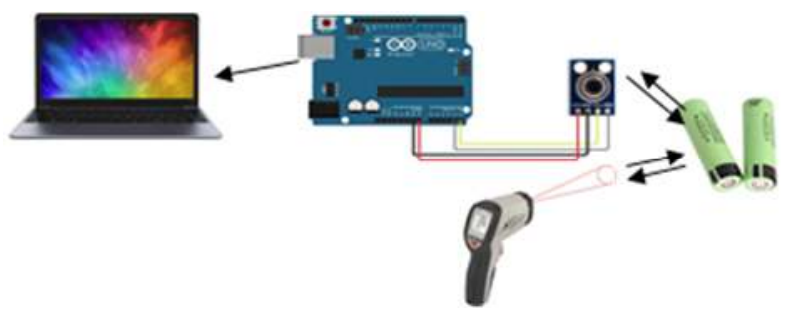

Gambar 7. Ilustrasi Kalibrasi Sensor Temperatur

Cara untuk melakukan kalibrasi sensor temperatur seperti gambar 7 di atas adalah dengan cara membandingkan dengan alat ukur temperatur contactless / infrared thermometer yang mempunyai spesifikasi range pembacaan dari $50^{\circ} \mathrm{C}-380^{\circ} \mathrm{C}$, dimana Arduino sudah terisi program untuk membaca nilai temperatur dari sensor MLX90614 yang akan di tampilkan lewat serial monitor IDE Arduino. Kedua sensor tersebut akan mengambil beberapa data temperatur yang kemudian dibandingkan untuk mendapatkan selisih hasil pembacaan temperatur.

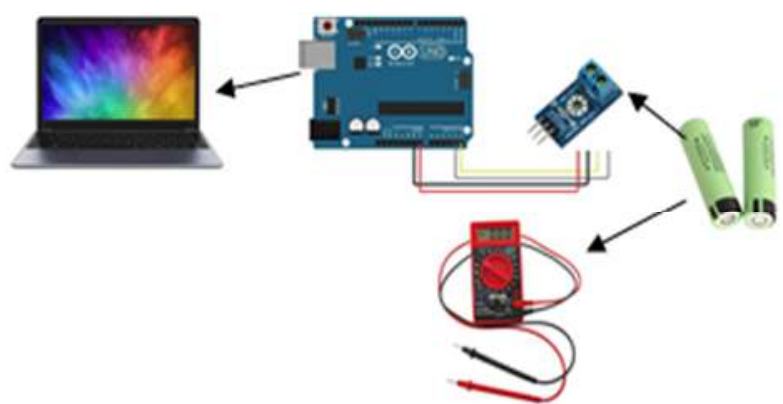

Gambar 8. Ilustrasi Kalibrasi Sensor Tegangan

Cara untuk melakukan kalibrasi sensor tegangan seperti gambar 8 di atas adalah dengan cara membandingkan dengan alat ukur multimeter yang di seting pada skala pembacaan tegangan yang mempunyai spesifikasi range pembacaan dari 0Volt - 20Volt, dimana Arduino sudah terisi program untuk membaca nilai tegangan dari sensor yang akan di tampilkan lewat serial monitor IDE Arduino. Kedua sensor tersebut akan mengambil beberapa data tegangan yang kemudian dibandingkan untuk mendapatkan selisih hasil pembacaan tegangande Penelitian / Metode merupakan prosedur atau teknik penelitian. Antara satu penelitian dengan penelitian yang lain, prosedur dan tekniknya bisa saja berbeda. Metode ditulis menggunakan font Times New Roman ukuran 12 pt dengan line spacing 1,0 antar baris dan paragraf dan untuk first linenya 0,8 . Adapun petunjuk penulisan arikel seperti penggunaan gambar dan tabel, penulisan formula matematika, singkatan dan akronim, serta rekomendasi lainnya. 
Jurnal ECOTIPE, Volume 7, No.1, April 2020, Hal. 26-37

p-ISSN 2355-5068, e-ISSN 2622-4852

Akreditasi Kemenristekdikti (SINTA 4), SK. No.10/E/KPT/2019

DOI: 10.33019/ecotipe.v7i1.1384

\section{HASIL PENELITIAN DAN PEMBAHASAN}

\section{A. Uji Coba Alat Fast Charger}

Untuk membuat alat Fast Charger ini ada beberapa komponen yang digunakan seperti gambar 9 di bawah ini:

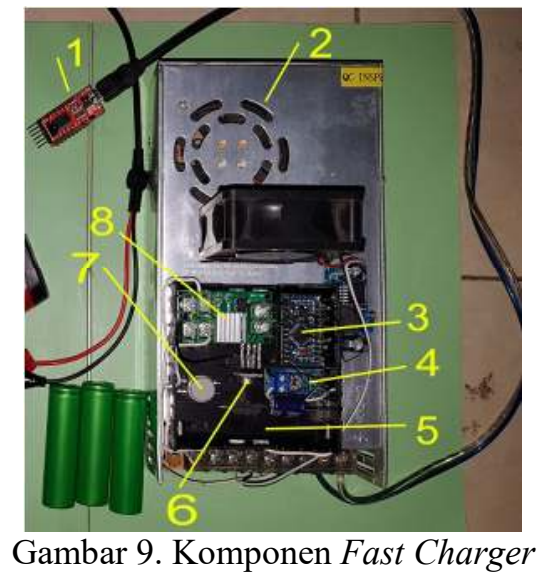

Keterangan:

1. USB to Serial

2. Power Supply $12 \mathrm{~V} / 10 \mathrm{~A}$

3. Mikrokontroler

4. Sensor Tegangan

5. Holder Baterai

6. Sensor Temperatur

7. Push Button

8. Driver Module MOSFET

Fungsi pada masing-masing alat pada rangkaian Fast Charger ini adalah USB to serial digunakan untuk membaca data hasil pembacaan sensor tegangan dan sensor temperatur oleh mikrokontroler untuk ditampilkan pada serial monitor. Sumber tegangan dan arus yang digunakan untuk mencatu daya alat ini menggunakan power supply 12V/10A. Untuk memulai pengisian baterai push button harus ditekan terlebih dahulu sehingga mikrokontroler akan mengaktifkan Pulse Width Modulation (PWM) di output-kan pada driver module MOSFET untuk mengisi baterai yang terpasang pada holder baterai.

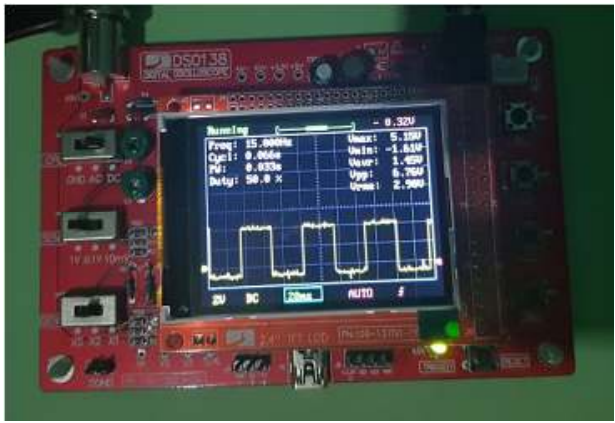

Gambar 10. Sinyal Output Pulse Width Modulation (PWM)

Pada gambar 10 di atas tampilan sinyal output PWM dengan duty cycle sebesar 50\% dengan frekuensi $15 \mathrm{~Hz}$ pada oscilloscope sesuai dengan program yang ditulis pada mikrokontroler.

\section{B. Hasil Kalibrasi Sensor Tegangan}

Rangkaian untuk mengkalibrasi sensor tegangan dengan menggunakan multimeter digital yang diatur pada skala 20 pembacaan tegangan DC dapat dilihat pada gambar 11 tujuannya adalah untuk membadingkan data pembacaan sensor dengan multimeter subelum digunakan untuk data input logika fuzzy.

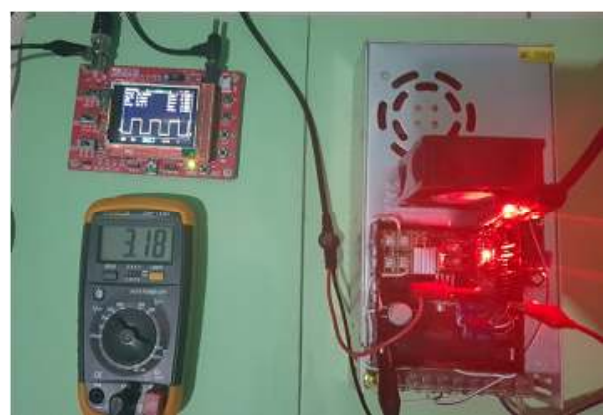

Gambar 11. Rangkaian Kalibrasi Sensor Tegangan Dengan Multimeter

Hasil kalibrasi sensor tegangan dengan menggunakan multimeter yang diatur pada skala pembacaan tegangan DC didapat data seperti tabel 2 di bawah ini. 
Jurnal ECOTIPE, Volume 7, No.1, April 2020, Hal. 26-37

p-ISSN 2355-5068, e-ISSN 2622-4852

Akreditasi Kemenristekdikti (SINTA 4), SK. No.10/E/KPT/2019

DOI: 10.33019/ecotipe.v7i1.1384

Tabel 2. Data Kalibrasi Sensor Tegangan Dengan Multimeter

\begin{tabular}{|c|c|c|c|c|c|}
\hline Waktu & PWM & $\begin{array}{l}\text { Duty } \\
\text { Cycle }\end{array}$ & $\begin{array}{l}\text { ADC } \\
\text { In }\end{array}$ & $\begin{array}{l}\text { ADC } \\
\text { (Volt) }\end{array}$ & $\begin{array}{c}\text { Multimeter } \\
\text { (Volt) }\end{array}$ \\
\hline $21: 01: 45$ & 0 & 0 & 0 & 0 & 0 \\
\hline $21: 01: 50$ & 15 & 5,88 & 48,09 & 0,94 & 0,90 \\
\hline $21: 01: 55$ & 30 & 11,76 & 59,52 & 1,17 & 1,13 \\
\hline $21: 02: 00$ & 45 & 17,65 & 69,89 & 1,37 & 1,34 \\
\hline 21:02:05 & 60 & 23,53 & 79,77 & 1,56 & 1,54 \\
\hline $21: 02: 10$ & 75 & 29,41 & 89,43 & 1,75 & 1,74 \\
\hline $21: 02: 15$ & 90 & 35,29 & 98,41 & 1,93 & 1,93 \\
\hline $21: 02: 20$ & 105 & 41,18 & 107,25 & 2,1 & 2,11 \\
\hline $21: 02: 25$ & 120 & 47,06 & 115,83 & 2,27 & 2,29 \\
\hline $21: 02: 30$ & 135 & 52,94 & 123,81 & 2,43 & 2,46 \\
\hline $21: 02: 35$ & 150 & 58,82 & 131,88 & 2,59 & 2,63 \\
\hline $21: 02: 40$ & 165 & 64,71 & 139,45 & 2,73 & 2,79 \\
\hline $21: 02: 45$ & 180 & 70,59 & 148,09 & 2,9 & 2,95 \\
\hline $21: 02: 50$ & 195 & 76,47 & 156,44 & 3,07 & 3,10 \\
\hline $21: 02: 55$ & 210 & 82,35 & 164,12 & 3,22 & 3,25 \\
\hline $21: 03: 00$ & 225 & 88,24 & 166,36 & 3,26 & 3,28 \\
\hline $21: 03: 05$ & 240 & 94,12 & 166,43 & 3,26 & 3,29 \\
\hline $21: 03: 10$ & 255 & 100 & 166,46 & 3,26 & 3,29 \\
\hline
\end{tabular}

Dari pengambilan data sensor tegangan dan multimeter dimana nilai PWM yang di outputkan mulai dari 0 sampai 255 dibagi menjadi 18 macam data output. Didapat jarak antara pengukuran sensor tegangan ADC dan multimeter perbedaan pembacaan tegangan kecil, sehingga data dari hasil pembacaan sensor bisa langsung digunakan data input logika fuzzy.

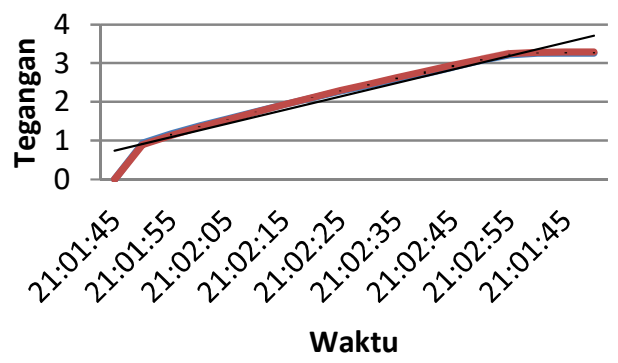

Gambar 12. Grafik Data Kalibrasi Sensor Tegangan Dengan Multimeter
Pada gambar 12 dapat dilihat perbedaan dari bentuk grafik yang ditampilkan dari data sensor tegangan baterai yang berwarna biru dengan alat ukur multimeter yang berwarna merah hasil pembacaan tidak jauh berbeda, sehingga tanpa melakukan perubahan pada program pembacaan sensor tegangan, data bisa langsung digunakan untuk input logika fuzzy.

\section{Hasil Kalibrasi Sensor Temperatur}

Rangkaian untuk mengkalibrasi sensor temperatur dengan menggunakan Infrared Thermometer yang mempunyai range pengukuran temperatur $-50^{\circ} \mathrm{C}$ sampai $380^{\circ} \mathrm{C}$ dapat dilihat pada gambar 13 tujuannya adalah untuk membandingkan data pembacaan sensor dengan Infrared Thermometer sebelum digunakan untuk data input logika fuzzy

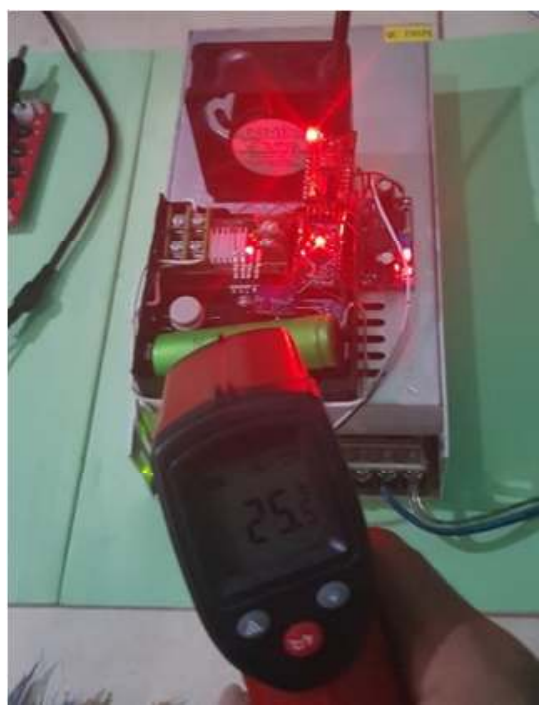

Gambar 13. Rangkaian Kalibrasi Sensor Temperatur Dengan Infrared Thermometer

Hasil kalibrasi sensor temperatur dengan menggunakan Infrared Thermometer tanpa harus menempelkan alat ukur dengan badanlcasing baterai didapat data seperti tabel 3 di bawah ini. 
Jurnal ECOTIPE, Volume 7, No.1, April 2020, Hal. 26-37

p-ISSN 2355-5068, e-ISSN 2622-4852

Akreditasi Kemenristekdikti (SINTA 4), SK. No.10/E/KPT/2019

DOI: 10.33019/ecotipe.v7i1.1384

Tabel 3. Data Kalibrasi Sensor Temperatur Dengan Infrared Thermometer

\begin{tabular}{|c|c|c|c|}
\hline Waktu & $\begin{array}{c}\text { Temperatur } \\
\text { ADC }\end{array}$ & $\begin{array}{c}\text { Baterai } \\
\left({ }^{\circ} \mathbf{C}\right)\end{array}$ & $\begin{array}{c}\text { Infrared } \\
\text { Thermometer }\left({ }^{\circ} \mathbf{C}\right)\end{array}$ \\
\hline $21: 01: 45$ & 139,28 & 27,31 & 27,60 \\
\hline $21: 01: 50$ & 139,18 & 27,29 & 27,60 \\
\hline $21: 01: 55$ & 139,18 & 27,29 & 27,60 \\
\hline $21: 02: 00$ & 139,18 & 27,29 & 27,60 \\
\hline $21: 02: 05$ & 138,77 & 27,21 & 27,60 \\
\hline $21: 02: 10$ & 139,49 & 27,35 & 27,60 \\
\hline $21: 02: 15$ & 139,49 & 27,35 & 27,60 \\
\hline $21: 02: 20$ & 139,28 & 27,31 & 27,60 \\
\hline $21: 02: 25$ & 139,18 & 27,29 & 27,60 \\
\hline $21: 02: 30$ & 139,28 & 27,31 & 27,60 \\
\hline $21: 02: 35$ & 139,79 & 27,41 & 27,60 \\
\hline $21: 02: 40$ & 139,49 & 27,35 & 27,60 \\
\hline $21: 02: 45$ & 139,28 & 27,31 & 27,60 \\
\hline $21: 02: 50$ & 139,28 & 27,31 & 27,60 \\
\hline $21: 02: 55$ & 139,28 & 27,31 & 27,60 \\
\hline $21: 03: 00$ & 139,59 & 27,37 & 27,60 \\
\hline $21: 01: 45$ & 139,28 & 27,31 & 27,60 \\
\hline $21: 01: 50$ & 139,18 & 27,29 & 27,60 \\
\hline
\end{tabular}

Dari pengambilan data sensor temperatur baterai dan Infrared Thermometer dimana nilai temperatur yang di outputkan perbedaan pembacaan temperatur kecil, sehingga data dari hasil pembacaan sensor bisa langsung digunakan data input logika fuzzy.perbedaan pembacaan terjadi karena terpengaruh dari suhu ruangan ketika melakukan percobaan.

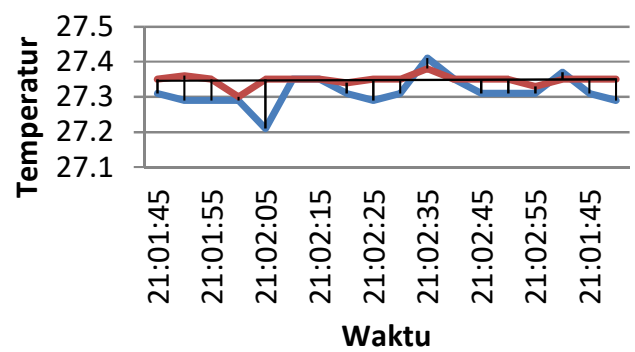

Gambar 14. Grafik Tegangan Pengisian Baterai Dengan Waktu

Pada gambar 14 dapat dilihat perbedaan dari bentuk grafik yang ditampilkan dari data sensor temperatur baterai yang berwarna biru dengan alat ukur Infrared Thermometer yang berwarna merah hasil pembacaan temperatur cukup berbeda, karena selain dipengaruhi oleh suhu ruangan pada saat melakukan pengukuran bisa juga karena pengambilan/posisi alat ukur kurang tepat. Walaupun ada selisih dari pembacaan sensor dengan alat ukur data masih bisa digunakan, sehingga tanpa melakukan perubahan pada program pembacaan sensor temperatur data bisa langsung digunakan untuk input logika fuzzy.

\section{Uji Fungsi Cutoff Jika Pengisian Penuh}

Proses pengujian fungsi cutoff ini berfungsi dengan baik untuk memutus atau menghentikan proses pengisian baterai pada saat mencapai tegangan yang diingikan. Selain dapat memutus pengisian daya listrik, fungsi cutoff dapat mencegah terjadinya overcharging yang dapat menaikan temperatur baterai dan dapat merusak baterai/meledak.

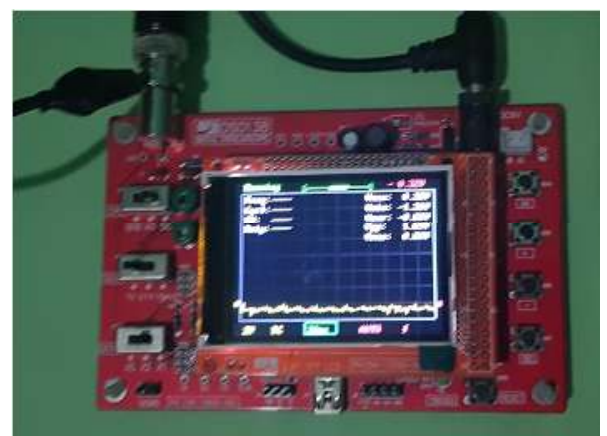

Gambar 15. Sinyal Output PWM 0 Saat Baterai Penuh

Sinyal output PWM yang diperlihatkan pada gambar 15 di atas dapat dilihat bawah fungsi program untuk cutoff berfungsi dengan baik dengan memberi sinyal PWM sebesar 0 untuk menghentikan pengisian baterai.

\section{E. Pengambilan Data Tegangan Baterai Saat Pengisian}

Hasil pengambilan data tegangan baterai saat melakukan pengisian dengan menggunakan alat Fast Charger didapat data seperti gambar 5.8 di bawah ini. 


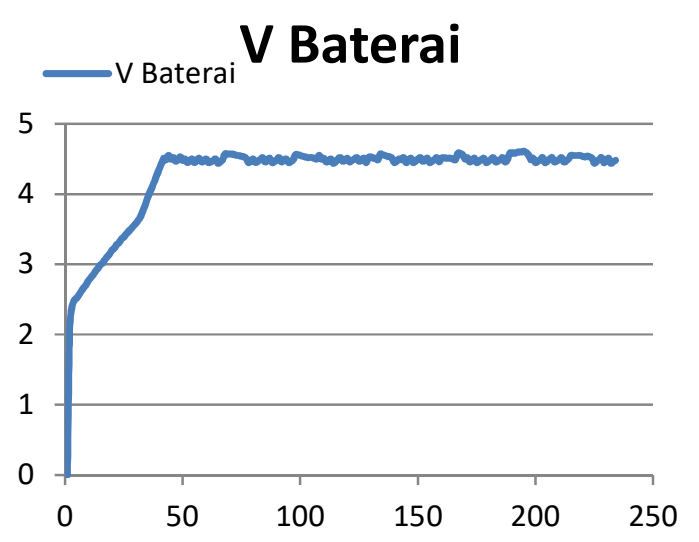

Gambar 16. Grafik Tegangan Pengisian Baterai

Pada gambar 16 bentuk grafik yang ditampilkan dari hasil pembacaan 234 data sensor tegangan yang berwarna biru, kenaikan tegangan sangat cepat dari data 0 sampai ke 48 ada pada tegangan 4,5Volt. Tegangan 4,5Volt ini diperoleh dari tegangan balik dari baterai dengan tegangan charger karena seiring kapasitas baterai bertambah, hambatan dalam baterai juga ikut bertambah sehingga tegangan yang terbaca dari sensor ikut bertambah.

\section{F. Pengambilan Data Temperatur Baterai Saat Pengisian}

Hasil pengambilan data temperatur baterai saat melakukan pengisian dengan menggunakan alat Fast Charger didapat data seperti gambar 17 di bawah ini.

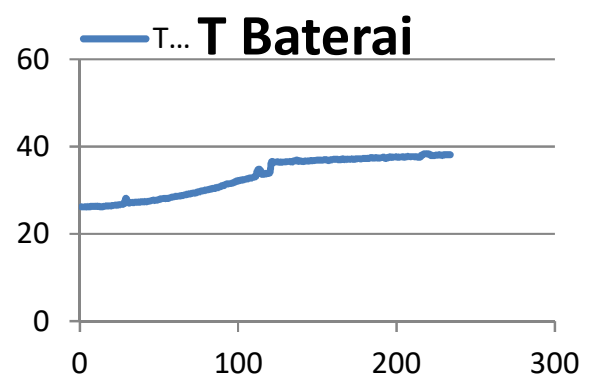

Gambar 17. Grafik Temperatur Pengisian Baterai

Pada gambar 17 bentuk grafik yang ditampilkan dari hasil pembacaan 234 data sensor temperatur baterai yang berwarna biru terus bertambah, karena pada saat melakukan pengisian selain tegangan baterai dan kapasitas baterai terus bertambah, temperatur juga akan terur menerus bertambah. Pada data ke 110 keatas, kenaikan temperatur tidak terlalu besar kenaikannya karena kapasitas baterai sudah mulai penuh.

\section{G. Pengambilan Data Lama Waktu Pengisian}

Hasil pengambilan data lama waktu baterai saat melakukan pengisian dengan menggunakan alat Fast Charger didapat data seperti gambar 18 di bawah ini.

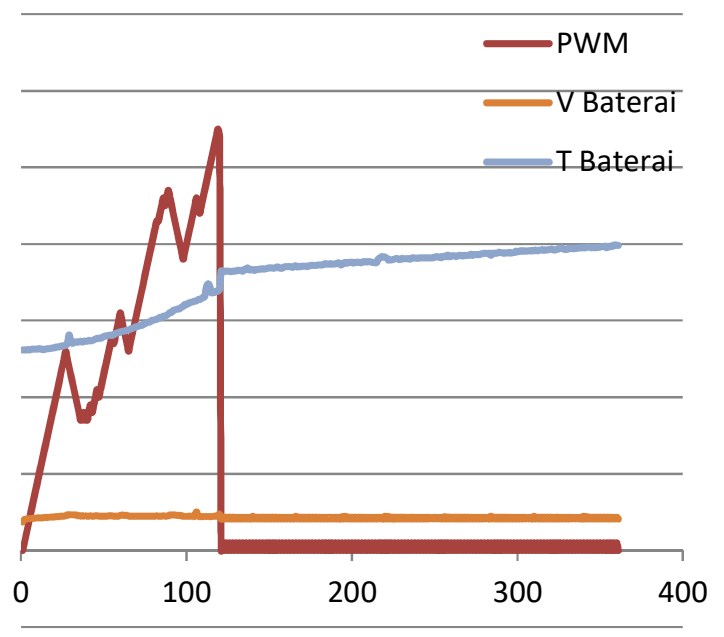

Gambar 18. Grafik Lama Waktu Pengisian Baterai

Pada gambar 18 bentuk grafik yang ditampilkan dari hasil pembacaan 361 data sensor tegangan, temperatur, dan nilai PWM. Kenaikan temperatur cukup cepat dari data 0 sampai ke 124 , setelah itu cenderung stabil karena kapasitas baterai mulai penuh diikuti nilai PWM yang turun. Sedangkan data PWM naik turun sangat sangat cepat sesuai dengan tegangan baterai yang terbaca oleh sensor tegangan. Ketika baterai sudah penuh PWM akan bernilai 0 untuk memutus pengisian baterai. 
Jurnal ECOTIPE, Volume 7, No.1, April 2020, Hal. 26-37

p-ISSN 2355-5068, e-ISSN 2622-4852

Akreditasi Kemenristekdikti (SINTA 4), SK. No.10/E/KPT/2019

DOI: 10.33019/ecotipe.v7i1.1384

\section{KESIMPULAN}

Pada penelitian ini telah didesain perangkat Fast Charger yang menggunakan teknik fast charging baterai lithium-ion menggunakan logika fuzzy. Desain terdiri dari perangkat hardware dan software. Rangkaian Fast Charger yang telah didesain mampu bekerja sesuai dengan sensor yang terpasang. Dari hasil pengujian kalibrasi setiap sensor dapat mengukur tegangan dan mampu mengukur temperatur baterai dengan baik. Untuk pembatasan suhu dibatasi sesuai dengan aturan standar baterai lithium-ion, yaitu $0^{\circ} \mathrm{C}$ sampai $45^{\circ} \mathrm{C}$. Desain sistem teknik pengisian fast charging baterai lithium-ion menggunakan logika fuzzy telah dikembangkan pada penelitian ini yaitu, peningkatan kecepatan pengisian dan melindungi dari overcharging yang telah dibuktikan pada data yang sudah dipaparkankan.

\section{DAFTAR PUSTAKA}

[1] Ahmad Faiz Farizy, Dimas Anton Asfani, dan Soedibjo. (2016). Desain Sistem Monitoring State of Charge Baterai pada Charging Station Mobil Listrik Berbasis Fuzzy Logic Dengan Mempertimbangkan Temperature. JURNAL TEKNIK ITS Vol. 5, No. 2, (2016) ISSN: 2337-3539 (23019271 Print).

[2] Budiono. (2003). Implementasi Mikrokontroler ATMEL AT90S8535 Pada Manajemen Energi. Tesis. Tidak dipublikasikan. Institut Teknologi Bandung (ITB).

[3] Bundit Tanboonjit, Nisai H. Fuengwarodsakul. (2014). Implementation of Charger and Battery Management System for Fast Charging Technique of $\mathrm{Li}$-FePO4 Battery in Electric Bicycles. 978-1-47993787-5/14/\$31.00 C2014 IEEE.

[4] Chia-Hsiang Lin, Chi-Lin Chen,Yu-Huei Lee,Shih-Jung Wang, Chun-Yu Hsieh,Hong-
Wei Huang, and Ke-Horng Chen. (2008). Fast Charging Technique for Li-Ion Battery Charger. 978-1-4244-2182-4/08/\$25.00 (C)2008 IEEE.

[5] Chun-Liang Liu, Shun-Chung Wang, Yi-Hua Liu, Meng-Chung Tsai. (2012). An Optimum Fast Charging Pattern Search for Li-Ion Batteries Using Particle Swarm Optimization. SCIS-ISIS 2012, Kobe, Japan, November 20-24, 2012.

[6] C.K.Leong, YH Can, C.D Can, Z. Y Phuan, M.K Yoong, B.K Cheah. K. W Chew. (2010). Ultra Fast Charging System On Lithium Ion Battery. Proceedings of the 2010 IEEE Conference on Sustainable Utilization and Development in Engineering and Technology Universiti Tunku Abdul Rahman 20 \& 21 November 2010, Faculty of Engineering, Kuala Lumpur, Malaysia.

[7] EEMB Co., Ltd. (2010). Lithium-ion Battery DATA SHEET. LIR18650 Datasheet Li-ion Battery Edition: NOV. 2010.

[8] EEMB Co., Ltd. (2016). Lithium-ion Battery DATA SHEET. LIR18650 Datasheet Li-ion Battery Edition: Aug. 2016.

[9] Houshyar Asadi, S.Hr.Aghay Kaboli, Arash Mohammadi , Maysam Oladazimi. (2011). Fuzzy Logic Control Technique in Li-Ion Battery Charger. International Conference on Electrical, Electronics and Civil Engineering (ICEECE'2011) Pattaya Dec. 2011.

[10] Indar Sugiarto, Lauw Lim Un Tung. (2004). Smart Charger NiCd dan NiMh Dengan Teknik Pengisian Pulsa. Proceedings, Komputer dan Sistem Intelijen (KOMMIT2004) Auditorium Universitas Gunadarma, Jakarta, 24-25 Agustus 2004 ISSN:1411-6286.

[11] Jingyu Yan, Guoqing Xu, Huihuan Qian, Yangsheng Xu. (2010). Battery Fast Charging Strategy Based on Model Predictive Control. 978-1-4244-35746/10/\$25.00 (C2010 IEEE. 
Jurnal ECOTIPE, Volume 7, No.1, April 2020, Hal. 26-37

p-ISSN 2355-5068, e-ISSN 2622-4852

Akreditasi Kemenristekdikti (SINTA 4), SK. No.10/E/KPT/2019

DOI: $10.33019 /$ ecotipe.v7i1.1384

[12] J. Lopez, M. Godlez, J. C. Viera, C. Blanco. (2004). Fast-Charge in Lithium-Ion Batteries for Portable Applications. 0-78038458-X/04/\$20.00 C2004 IEEE.

[13] M. Gonzalez, M.A. Perez, J.C. Campo, F.J. Ferrero. (1998). Accurate Detection Algorithm of Battery Full-Capacity Under Fast-Charge. $\quad 0-7803-4797-8 / 98 / \$ 10.00$ 1998 IEEE.

[14] R.J. Wai, S.J. Jhung. (2012). Design of energy-saving adaptive fast-charging control strategy for Li-FePO4battery module. IET Power Electron., 2012, Vol. 5, Iss. 9, pp. 1684-1693.

[15] Ruei-Hong Peng, Tsu-Wei Tsai, Ke-Horng Chen, Zhih Han Tai, Yi Hsuan Cheng, Chi Chung Tsai, Hsin-Yu Luo, Shih-Ming Wang, Long-Der Chen, Cheng-Chen Yang, and JuiLung Chen. 2013. Switching-based Charger with Continuously Built-in Resistor Detector (CBIRD) and Analog Multiplication-division Unit (AMDU) for Fast Charging in Li-ion Battery. $\quad 978-1-4799-0645-1 / 13 / \$ 31.00$ (C)2013 IEEE.

[16] Technical Handbook. Lithium Ion Rechargeable Batteries.

[17] Yu-Chun Huang, Wei-Song Lin. (2011). Charge Shuttling with Ultracapacitors for Fast Equalization of Power Lithium-ion Battery. 978-1-4577-21199/12/\$26.00@2011 IEEE.

[18] Yong-Duk Lee and Sung-Yeul Park. (2013). Rapid Charging Strategy in the Constant Voltage Mode for a High Power Li-Ion Battery. $\quad 978-1-4799-0336-8 / 13 / \$ 31.00$ (C)2013 IEEE 